\title{
The Acid Hydrolysis Mechanism of Acetals \\ Catalyzed by a Supramolecular Assembly in Basic Solution
}

Michael D. Pluth, Robert G. Bergman, * and Kenneth N. Raymond*

\begin{abstract}
Contribution from the Department of Chemistry, University of California, Berkeley, and Division of Chemical Sciences, Lawrence Berkeley National Laboratory, Berkeley, California, 94720, USA
\end{abstract}

Corresponding Authors:

Prof. Robert G. Bergman, Prof. Kenneth N. Raymond, Department of Chemistry, University of California, Berkeley, CA 94720-1460 (USA). Fax: (+1) 510-642-7714 (Bergman). Fax: (+1) 510-486-5283 (Raymond). E-mail: rbergman@ berkeley.edu, raymond@socrates.berkeley.edu 


\begin{abstract}
A self-assembled supramolecular host catalyzes the hydrolysis of acetals in basic aqueous solution. The mechanism of hydrolysis is consistent with the Michaelis-Menten kinetic model. Further investigation of the rate limiting step of the reaction revealed a negative entropy of activation $\left(\Delta S^{\ddagger}=-9 \mathrm{cal} \mathrm{mol}^{-1} \mathrm{~K}^{-1}\right)$ and an inverse solvent isotope effect $\left(k\left(\mathrm{H}_{2} \mathrm{O}\right) / k\left(\mathrm{D}_{2} \mathrm{O}\right)=0.62\right)$. These data suggest that the mechanism of hydrolysis that takes place inside the assembly proceeds through an A-2 mechanism, in contrast to the A1 mechanism operating in the uncatalyzed reaction. Comparison of the rates of acetal hydrolysis in the assembly with the rate of the reaction of unencapsulated substrates reveals rate accelerations of up to 980 over the background reaction for the substrate diethoxymethane.
\end{abstract}

\title{
Introduction
}

Supramolecular reactivity has advanced over the past decade to include a number of supramolecular host molecules able to catalyze chemical reactions within their interior cavities. $^{1-5}$ While stoichiometric reactivity has produced remarkable examples of both enhanced selectivity and changes in reactivity, ${ }^{6-14}$ product inhibition has often prohibited catalytic turnover. $^{7,12,15}$ In order to abate this problem, a number of strategies including changing the substrate or relying on further reactivity of the product following escape from the cavity, have been employed in order prevent re-encapsulation of the product. ${ }^{16,17}$ In contrast to transition-metal catalysts or organocatalysts, supramolecular catalysis does not necessarily employ covalent interactions between the substrate and host molecule. 
This has yielded valuable information on how weak interactions can work in concert to affect reactivity.

Although electrocyclic reactions received much early attention in studies of supramolecular reactivity, due to the ability of the cavities of synthetic hosts cavities to preorganize substrates in reactive conformations or to increase the effective concentrations of the reactants in the cavity of the molecular hosts, ${ }^{18,19}$ other types of reactivity have more recently been explored. For example, a number of supramolecular host molecules have been utilized to affect the hydrolysis of substrates in their interior cavities. The alcoholysis of alkyl halides has been accomplished with size selectivity with assemblies able to concentrate solvent molecules inside of their interior cavities. ${ }^{20}$ Similarly, $\beta$-cyclodextrin has been used to catalyze the hydrolysis of acetals at neutral $\mathrm{pH} .{ }^{21}$ Furthermore, the simple modification of cyclodextrins has been explored to change the guest binding preferences and acidity of pendant hydroxyl groups on the periphery of the cyclodextrins. ${ }^{22-25}$ These functionalized cyclodextrins are active catalysts for the hydrolysis of encapsulated glycosides near physiological pH. Depending on the substrate, $\mathrm{pH}$, and cyclodextrin functionalization, rate accelerations of up to 8000 have been observed with respect to the background hydrolysis reaction. ${ }^{26}$

Over the past decade, Raymond and co-workers have used the strategy of selfassembly to develop tetrahedral $\mathrm{M}_{4} \mathrm{~L}_{6}\left(\mathrm{M}=\mathrm{Ga}^{\mathrm{III}}(\mathbf{1}), \mathrm{Al}^{\mathrm{III}}, \mathrm{In}^{\mathrm{III}}, \mathrm{Fe}^{\mathrm{III}}, \mathrm{Ti}^{\mathrm{IV}}\right.$, or $\mathrm{Ge}^{\mathrm{IV}}, \mathrm{L}=$ $N, N^{\prime}$-bis(2,3-dihydroxybenzoyl)-1,5-diaminonaphthalene) supramolecular assemblies (Figure 1). ${ }^{27,28}$ Although $\mathbf{1}$ is water-soluble it maintains a hydrophobic interior cavity able to isolate encapsulated guests from bulk solution. ${ }^{28,29}$ Monocationic guests are preferentially encapsulated in $\mathbf{1}$ but neutral hydrophobic guests are also bound. ${ }^{30}$ 
Although isolated from bulk solution, encapsulated guests are able to exchange into and out of 1 by dilation of the 3 -fold symmetric apertures of the assembly. ${ }^{31}$ The host assembly 1 has been used to mediate both stoichiometric and catalytic organometallic reactions and has been used as a catalyst for the sigmatropic rearrangement of enammonium cations. ${ }^{16,32,33}$ Furthermore, the protonation of encapsulated guests has been investigated and has revealed $\mathrm{p} K_{\mathrm{a}}$ shifts of up to $4.5 \mathrm{p} K_{\mathrm{a}}$ units for encapsulated protonated amines ${ }^{34}$ and has allowed for the observation and quantification of hydrogen bond breaking followed by nitrogen inversion/rotation of encapsulated protonated diamines. ${ }^{35}$ The thermodynamic stabilization of protonated guests and has been further exploited for the catalytic hydrolysis of orthoformates and acetals in $\mathbf{1} .^{17,36,37}$ Herein we expand upon our initial report of the scope of acetal hydrolysis in $\mathbf{1}$ to include a detailed study of the mechanism of this reaction.
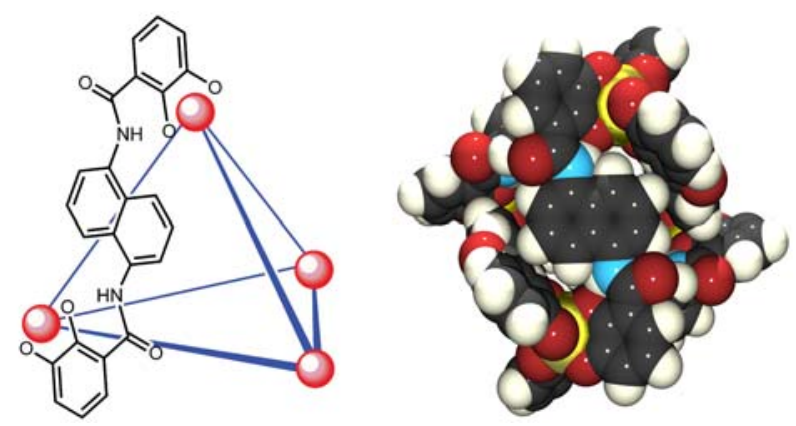

Figure 1. (Left) A schematic representation of $\mathbf{1}$ with only one ligand shown for clarity. (Right) A space-filling model of $\mathbf{1}$ as viewed down the 2-fold axis defined by the naphthalene-based ligand.

\section{Results and Discussion}

Acetals are a common protecting group for ketones and aldehydes in organic synthesis and are generally hydrolyzed by the use of Brønsted or Lewis acid catalysts in 
the presence of water. More recently, a number of mild methods for acetal deprotection have been reported which include Lewis acids such $\mathrm{Bi}(\mathrm{III})$ or $\mathrm{Ce}(\mathrm{III})$ or reagents supported on silica. ${ }^{38-42}$ Also of importance is that Markó and co-workers recently reported an example of acetal deprotection under mildly basic conditions using catalytic cerium ammonium nitrate at $\mathrm{pH} 8$ in a water-acetonitrile solution. ${ }^{43}$ In our initial communication of acetal hydrolysis, ${ }^{37}$ we demonstrated that $\mathbf{1}$ was a viable catalyst for the hydrolysis of acetals in basic solution under mild conditions $(\mathrm{pH} 10,5 \mathrm{~mol} \% \mathbf{1}, 6$ hours, $87-95 \%$ conversion, $79-92 \%$ isolated yield) (Scheme 1). With the intention of better understanding how the catalysis in $\mathbf{1}$ occurs, we investigated the mechanism of the process. The acetal 2,2-dimethoxypropane (2) was chosen as a substrate due to its convenient water solubility and the solubility of both of the hydrolysis products (acetone and methanol). ${ }^{44}$ As reported in our initial communication, $\mathbf{2}$ is quickly hydrolyzed by $\mathbf{1}$ but the hydrolysis can be inhibited by the addition of a strongly binding guest such as $\mathrm{NEt}_{4}^{+}\left(\log \left(K_{\mathrm{a}}\right)=4.55\right)$.

$$
\underset{\mathrm{R}^{1}}{\mathrm{MeO}} \mathrm{R}_{\mathrm{R}^{2}}^{\mathrm{OMe}} \frac{5 \mathrm{~mol} \% 1}{\mathrm{H}_{2} \mathrm{O}, \mathrm{pH} \mathrm{10}} \underset{\mathrm{R}^{1}}{\stackrel{\mathrm{O}}{\mathrm{N}_{\mathrm{R}^{2}}}}+2 \mathrm{MeOH}
$$

Scheme 1. Catalytic deprotection of acetals under basic conditions using 1.

Although 2 was readily hydrolyzed by the assembly, separate resonances for the encapsulated substrate were not observed by ${ }^{1} \mathrm{H}$ NMR under the catalytic conditions but rather the resonances corresponding to the substrate were significantly broadened. For example, under catalytic conditions in the presence of $\mathbf{1}$, the peak width of the methoxy and methyl resonances of 2 are $v_{1 / 2}=19.7 \mathrm{~Hz}$ and $v_{1 / 2}=19.9 \mathrm{~Hz}$ respectively. Upon 
addition of 1.2 equivalents of $\mathrm{NEt}_{4}{ }^{+}$to the reaction mixture, the ${ }^{1} \mathrm{H}$ NMR resonances of the substrate sharpen to $v_{1 / 2}=2.8 \mathrm{~Hz}$ and $v_{1 / 2}=2.7 \mathrm{~Hz}$, which are nearly identical to the peak widths of $\mathbf{2}$ in the absence of $\mathbf{1}\left(v_{1 / 2}=2.5 \mathrm{~Hz}\right.$ and $v_{1 / 2}=2.7 \mathrm{~Hz}$ respectively) (Figure 2). These data suggest that the encapsulated and free acetal are rapidly exchanging on the NMR timescale, which prohibits observation of a kinetically stable host-substrate complex.
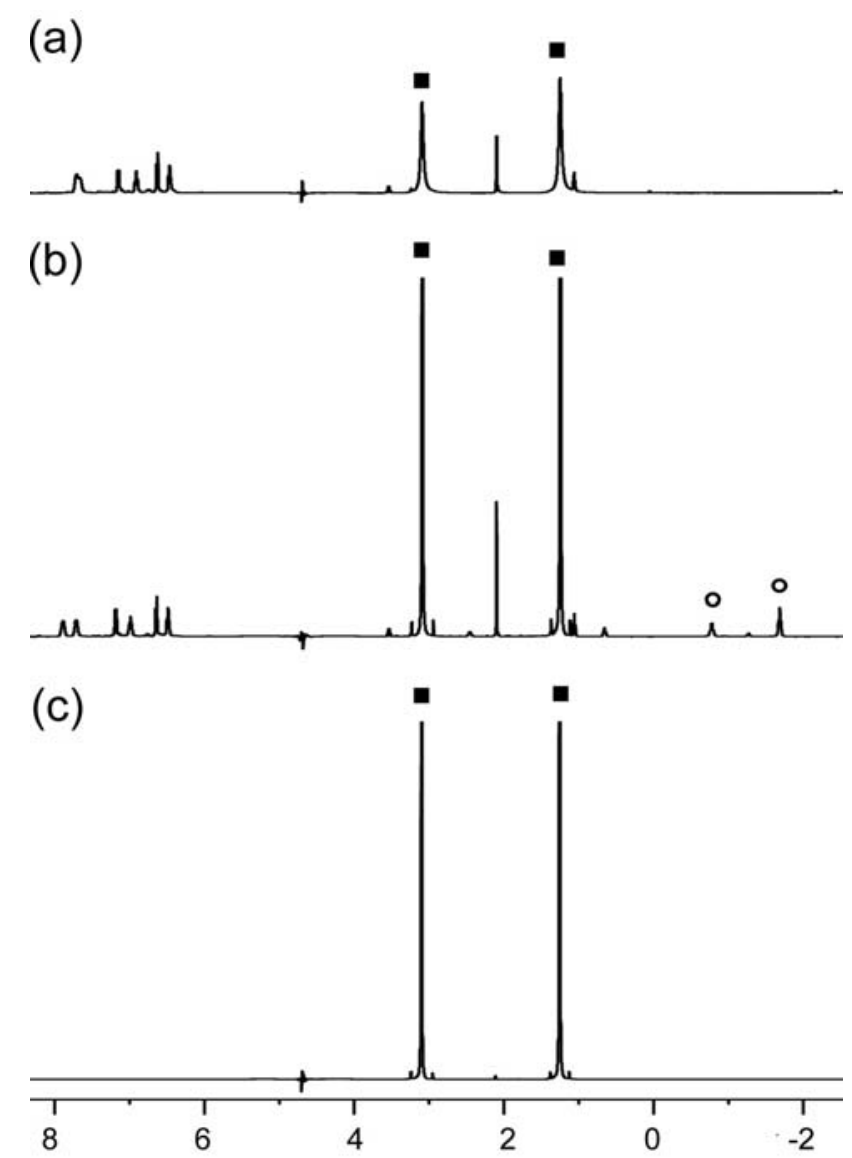

Figure 2. (a) ${ }^{1} \mathrm{H}$ NMR spectrum of 1 with 75 equivalents of 2 . (b) ${ }^{1} \mathrm{H}$ NMR spectrum after addition of one equivalent of $\mathrm{NEt}_{4}{ }^{+}$. (c) ${ }^{1} \mathrm{H}$ NMR spectrum $\mathbf{1}$ in $\mathrm{H}_{2} \mathrm{O}$ shown for comparison. All spectra were recorded at $\mathrm{pH} 10.0,100 \mathrm{mM} \mathrm{K}_{2} \mathrm{CO}_{3}, 22{ }^{\circ} \mathrm{C}$, in $\mathrm{H}_{2} \mathrm{O}$ with equal concentrations of 2 using Watergate solvent suppression. Key: 2 (๘), encapsulated $\mathrm{NEt}_{4}^{+}(\mathrm{O})$.

\section{Mechanistic Investigations}


Although small substrates such as $\mathbf{2}$ do not exhibit separate resonances for the bound and free material by ${ }^{1} \mathrm{H}$ NMR analysis under reaction conditions, more sterically bulky substrates, such as 2,2-dimethoxyadamantane (3) form observable host-guest complexes. ${ }^{37}$ The observation of encapsulated substrates under the catalytic reaction conditions suggests that neutral substrate encapsulation may be important in the catalytic cycle for all the acetals we have examined. In order to probe the importance of neutral substrate encapsulation for the smaller substrate 2, the observed rate of hydrolysis was monitored as a function of solvent composition. If the initial pre-equilibrium forming the host-substrate complex is driven by the hydrophobic effect, then the desolvation of the hydrophobic guest upon encapsulation should help drive the encapsulation process. If this is the case, then addition of organic solvents to an aqueous solution of $\mathbf{1}$ should inhibit the reaction by disfavoring the initial encapsulation of the substrate. ${ }^{45}$ In order to probe this hypothesis, a number of organic solvents ( $25 \%$ by volume), such as $d_{3}-\mathrm{MeOH}$, $d_{6}$-DMSO, $d_{7}$-DMF, or $d_{8}$-dioxane, were added to an aqueous solution of $\mathbf{1}$ under the catalytic conditions $\left(\mathrm{H}_{2} \mathrm{O}, \mathrm{pH} 10,50^{\circ} \mathrm{C}\right)$. In all cases, the addition of organic solvents greatly reduced the rate of product formation (Figure 3). ${ }^{46}$

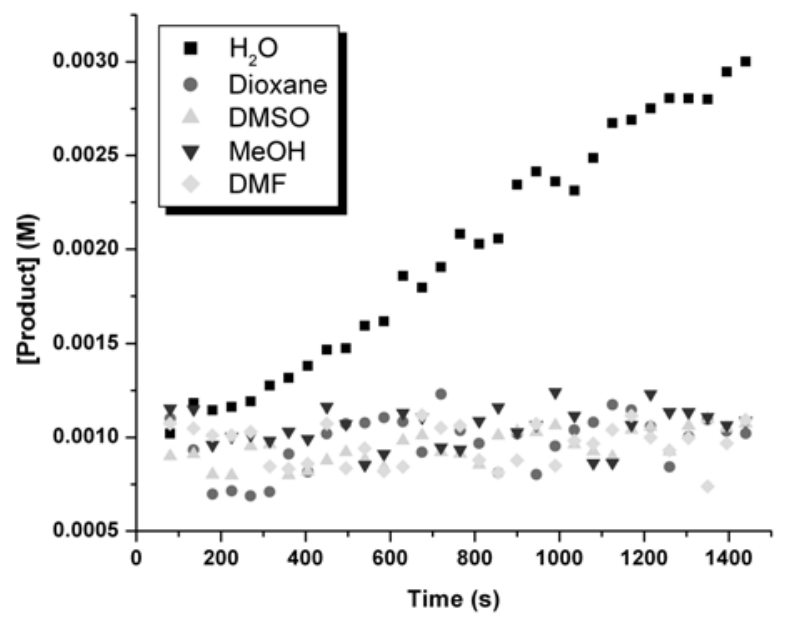

Figure 3. Solvent dependence on the initial rate of hydrolysis for 2. 
The fast guest exchange for smaller acetal substrates is analogous to the many systems whose rate behavior has been analyzed using the Michaelis-Menten kinetic formalism (including the mechanism for orthoformate hydrolysis in 1) in which a substrate binding pre-equilibrium occurs before the rate limiting step of the reaction. Having established the importance of the hydrophobic effect for substrate encapsulation in the catalysis, the kinetic order for [substrate], $[\mathbf{1}]$, and $\left[\mathrm{H}^{+}\right]$was determined. The rates were measured using 2 as the substrate at $50{ }^{\circ} \mathrm{C}$ with DMSO as an internal NMR integration standard. When the substrate concentration was increased while maintaining constant $\mathrm{pH}$ and concentration of $\mathbf{1}$, substrate saturation was observed that was consistent with the Michaelis-Menten formalism (Figure 4). In the substrate saturation regime of the reaction, the consumption of substrate and formation of product are pseudo zerothorder as expected (Figure 5). 

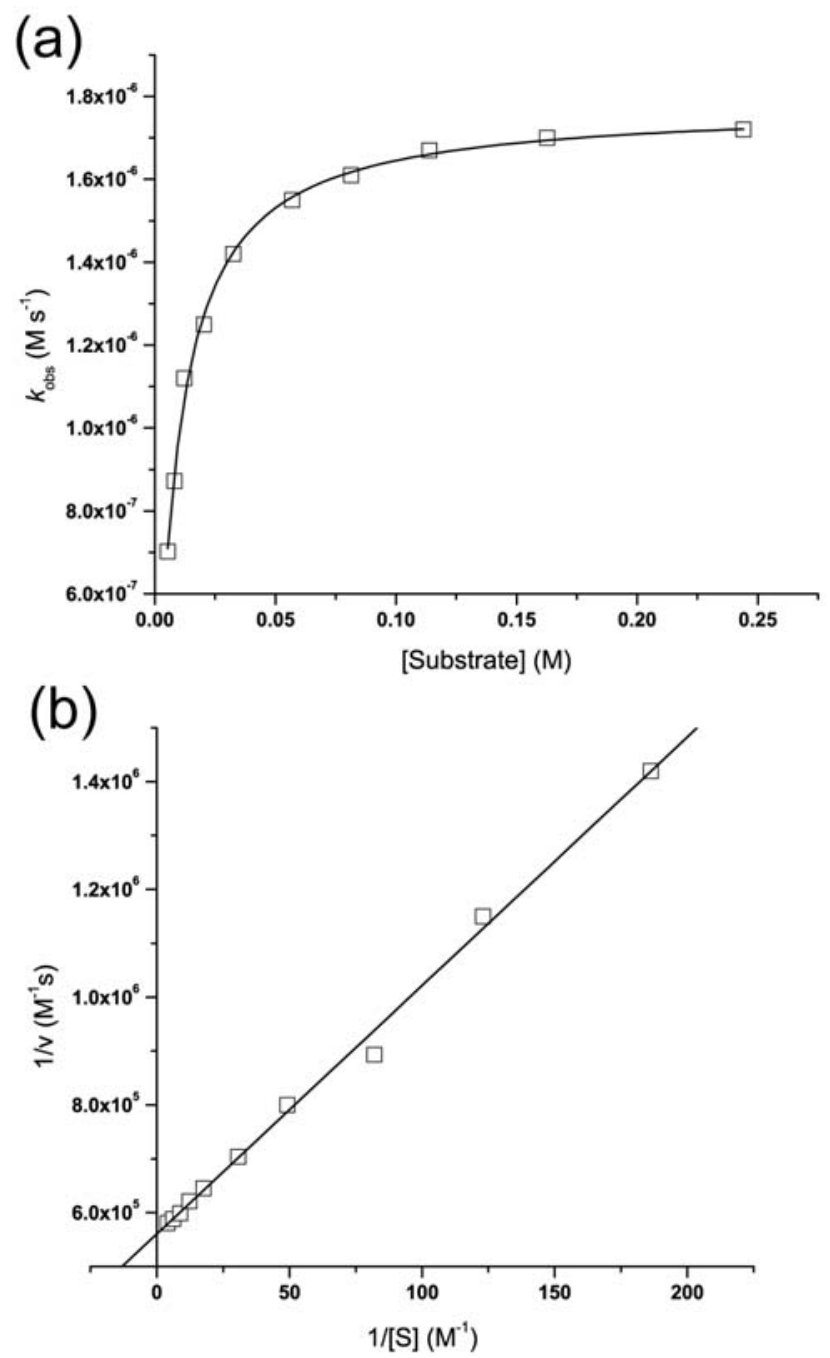

Figure 4. Rate dependence on [2] with catalytic 1 in $\mathrm{H}_{2} \mathrm{O}, \mathrm{pH} 10.0,100 \mathrm{mM} \mathrm{K}_{2} \mathrm{CO}_{3}, 50$ ${ }^{\circ} \mathrm{C}$. Substrate saturation is observed (a). The corresponding Lineweaver-Burke plot (b). 


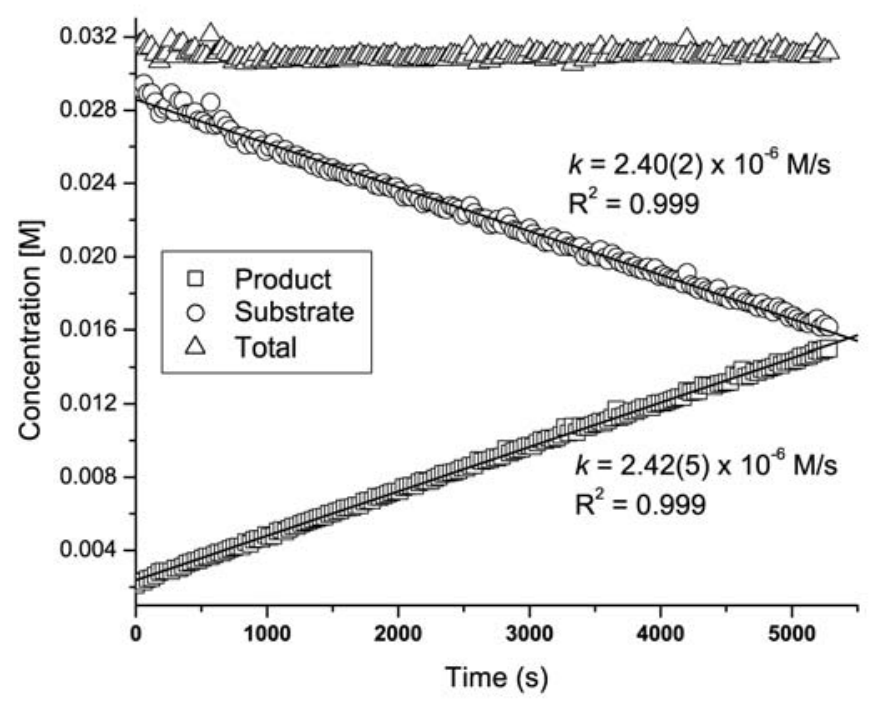

Figure 5. Substrate consumption and product formation are pseudo zeroth-order in the saturation regime of the catalyzed reaction.

In order to further elucidate the mechanism of catalysis, the overall rate law was determined. Working under the saturation conditions described above, kinetic analysis of the rate dependence on $\left[\mathrm{H}^{+}\right]$and $[\mathbf{1}]$ revealed that the reaction was first-order in both of these reaction partners (Figure 6). The combined kinetic data yielded the overall rate law: rate $=k\left[\mathrm{H}^{+}\right][$Substrate $][\mathbf{1}]$, which at saturation reduces to: rate $=k^{\prime}\left[\mathrm{H}^{+}\right][\mathbf{1}]$. 
(a)

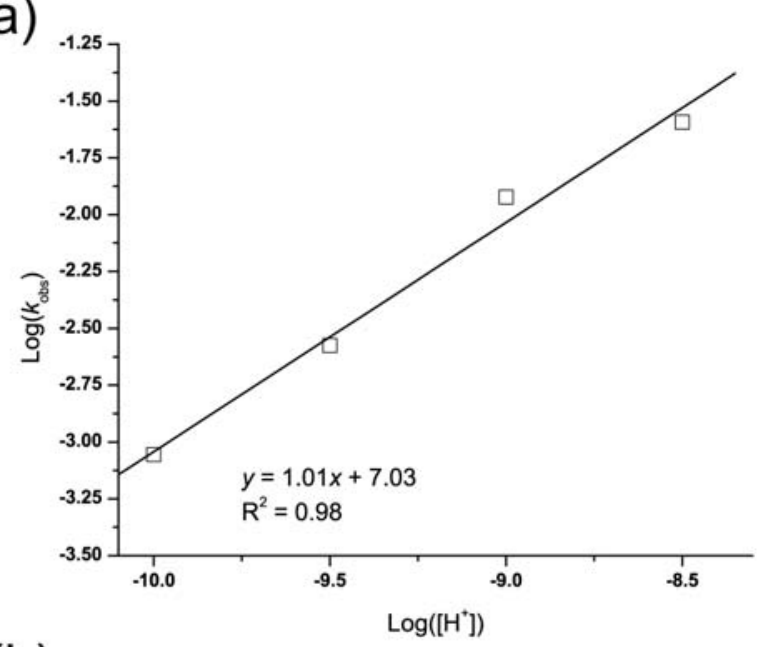

(b)

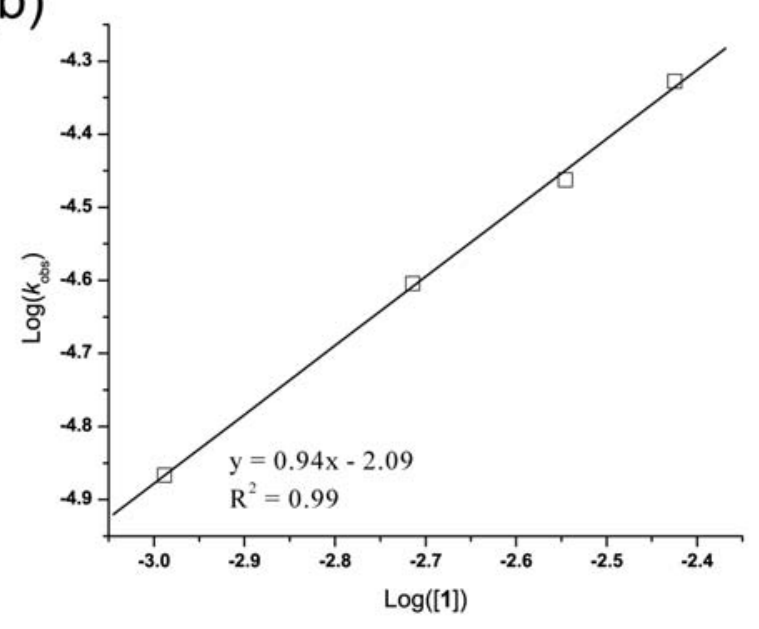

Figure 6. Rate dependence of $\left[\mathrm{H}^{+}\right]$and $[\mathbf{1}]$. (a) $\mathrm{pH}$ rate dependence of the hydrolysis of 2 in $\mathrm{H}_{2} \mathrm{O}$. (b) Rate dependence on [1] for the hydrolysis of 2 in $\mathrm{H}_{2} \mathrm{O}$.

In order to further characterize the rate-limiting step, the activation parameters and solvent isotope effect for the $k_{\text {cat }}$ step were determined. In free solution, the acidcatalyzed hydrolysis of acetals generally proceeds through an A-1 mechanism in which the substrate is in fast pre-equilibrium with its protonated analogue and decomposition of the latter species is rate-limiting. ${ }^{47-49}$ Mechanisms of this type are typically characterized by positive $\Delta S^{\ddagger}$ values ranging from +6 to $+10 \mathrm{cal} \mathrm{mol}^{-1} \mathrm{~K}^{-1}$ and inverse solvent isotope effects of $k\left(\mathrm{H}_{2} \mathrm{O}\right) / k\left(\mathrm{D}_{2} \mathrm{O}\right)=0.25-0.50$ reflecting the thermodynamics of the acid-base equilibrium. $^{47-49}$ By monitoring the reaction at different temperatures, the activation 
parameters for $k_{\text {cat }}$ were found to be $\Delta G^{\ddagger} 298 \mathrm{~K}=23(1) \mathrm{kcal} \mathrm{mol}^{-1}, \Delta H^{\ddagger}=21(1) \mathrm{kcal} \mathrm{mol}^{-1}$, and $\Delta S^{\ddagger}=-9(1) \mathrm{cal} \mathrm{mol}^{-1} \mathrm{~K}^{-1}$ (Figure 7). In order to determine the solvent isotope effect for the reaction, the $k_{\text {cat }}$ rate constant was determined in both $\mathrm{H}_{2} \mathrm{O}$ and $\mathrm{D}_{2} \mathrm{O}$ under identical conditions and was repeated at $\mathrm{pH} 10.0$ and $\mathrm{pH} 8.50 .^{50}$ The results were determined to be $k_{\text {cat }}\left(\mathrm{D}_{2} \mathrm{O}\right)=1.3 \times 10^{-3} \mathrm{~s}^{-1}$ and $k_{\text {cat }}\left(\mathrm{H}_{2} \mathrm{O}\right)=8.0 \times 10^{-4} \mathrm{~s}^{-1}$ at $\mathrm{pH} 10.0$ and $k_{\text {cat }}\left(\mathrm{D}_{2} \mathrm{O}\right)=2.8 \times 10^{-2} \mathrm{~s}^{-1}$ and $k_{\mathrm{cat}}\left(\mathrm{H}_{2} \mathrm{O}\right)=1.8 \times 10^{-2} \mathrm{~s}^{-1}$ at $\mathrm{pH} 8.50$ thereby affording an inverse solvent isotope effect of 0.62 .

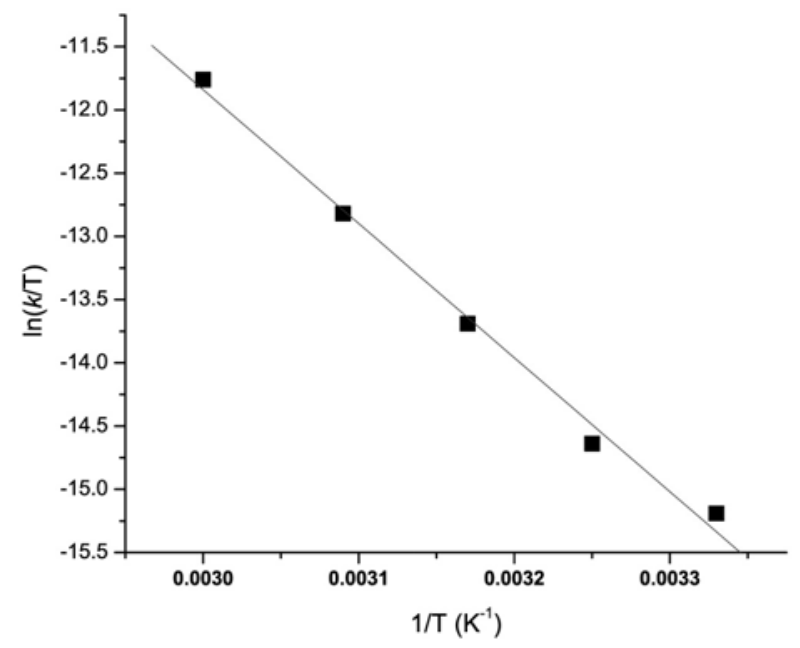

Figure 7. Eyring plot for the $k_{\text {cat }}$ rate constants determined from Michaelis-Menten analysis for the hydrolysis of 2 by $\mathbf{1}$ in $\mathrm{H}_{2} \mathrm{O}$, pH $10,50{ }^{\circ} \mathrm{C}$

The observed entropy of activation for catalysis in $\mathbf{1}$ of $-9(1) \mathrm{cal} \mathrm{mol}^{-1} \mathrm{~K}^{-1}$ is not consistent with the A-1 mechanism generally operational in acetal hydrolysis. The negative activation entropy shows that the transition state is more ordered than the ground state, suggesting a mechanism in which either attack of water on the protonated substrate is rate-limiting (A-2 mechanism) or proton-transfer from the acid (likely $\mathrm{H}_{3} \mathrm{O}^{+}$) is rate-limiting (A- $\mathrm{S}_{\mathrm{E}} 2$ mechanism) (Figure 8). ${ }^{49}$ The solvent isotope effects can be used 
to differentiate between these two possibilities. For A-2 hydrolysis mechanisms, nucleophilic attack of solvent on the protonated species is rate limiting and leads to large negative entropies of activation and inverse solvent isotope effects that are somewhat attenuated compared to those observed for A-1 mechanisms and generally range from $k\left(\mathrm{H}_{2} \mathrm{O}\right) / k\left(\mathrm{D}_{2} \mathrm{O}\right)=0.55-0.8 .^{47-49}$ In $\mathrm{A}-\mathrm{S}_{\mathrm{E}} 2$ hydrolysis mechanisms, the entropies of activation are also negative but proton transfer is rate-limiting which leads to a normal solvent isotope effect typically ranging from $1.3-4.0$ due to the difference in zero-point energy between $\mathrm{O}-\mathrm{H}$ and $\mathrm{O}-\mathrm{D}$ bonds.
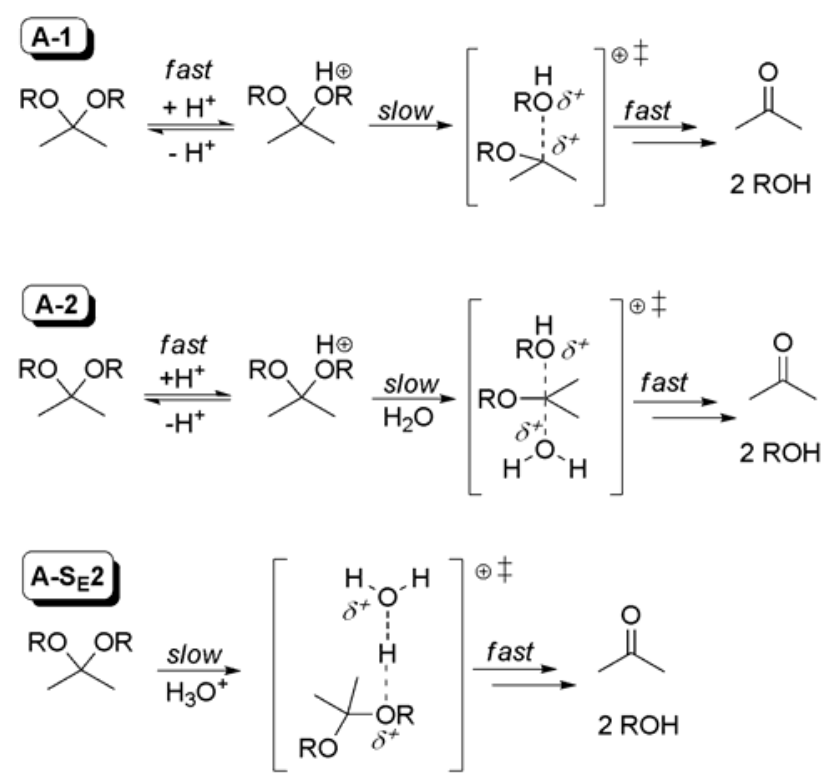

Figure 8. Mechanisms and transition states for A-1, A-2, and A-S 2 acetal hydrolysis. Acetal hydrolysis in 1 likely occurs through the A-2 transition state.

Analysis of the kinetic data suggests that acetal hydrolysis in $\mathbf{1}$ proceeds through an A-2 mechanism in which the protonation of the substrate is reversible and attack of water is rate limiting. The entropy of activation of $-9 \mathrm{cal} \mathrm{mol}^{-1} \mathrm{~K}^{-1}$ is similar to but slightly more 
negative than the $-5 \mathrm{cal} \mathrm{mol}^{-1} \mathrm{~K}^{-1}$ observed for hydrolysis of triethylorthoformate in $\mathbf{1}$ which was determined to proceed through an $\mathrm{A}-\mathrm{S}_{\mathrm{E}} 2$ mechanism. ${ }^{51}$

Based on the kinetic studies of acetal hydrolysis in $\mathbf{1}$, a proposed catalytic cycle for the hydrolysis reaction is shown in Figure 9. The neutral acetal substrate enters 1 to generate the resting state of the catalytic cycle at which point the substrate can be protonated by transiently encapsulated $\mathrm{H}_{3} \mathrm{O}^{+}$and then attacked by water in the ratelimiting step. We suggest that after protonation of the encapsulated substrate the resultant water molecule generated acts as a nucleophile inside the assembly although it is also possible that, despite the hydrophobic interior of $\mathbf{1}$, other water molecules are present in the interior cavity that could attack the protonated substrate. It should be noted that following this initial rate-limiting hydrolysis step, any of the remaining steps of the reaction can be either acid or base catalyzed, so is not possible to determine whether they take place inside $\mathbf{1}$ or in bulk solution after ejection following the rate-limiting step.

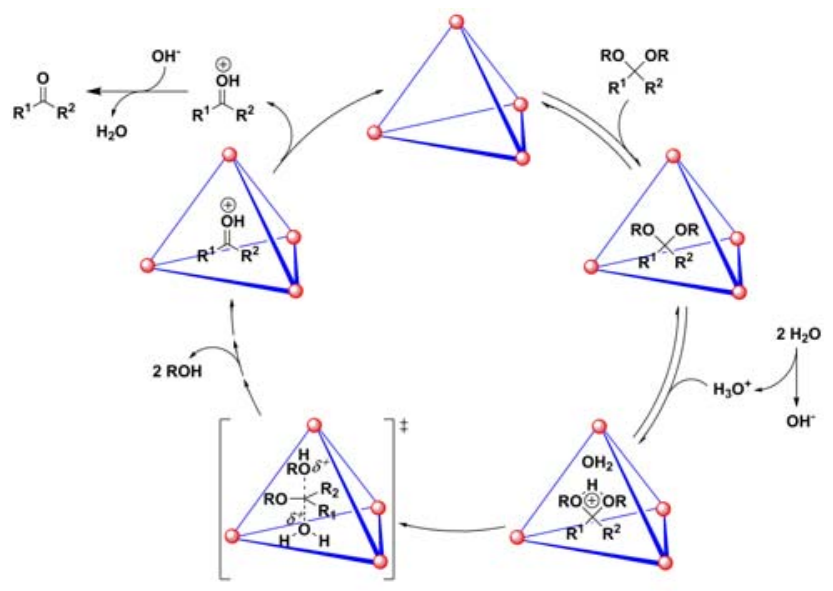

Figure 9. Proposed mechanism for acetal hydrolysis using 1 as a catalyst.

It is noteworthy that the mechanisms of acetal hydrolysis in $\mathbf{1}$ and the orthoformate hydrolysis studied earlier proceed through different rate-limiting steps. The 
intracavity orthoformate hydrolysis proceeds through an $\mathrm{A}-\mathrm{S}_{\mathrm{E}} 2$ mechanism in which proton transfer from the acid to the substrate is the rate limiting step. This is in contrast to the rate limiting attack of solvent on encapsulated protonated acetals. The observed difference in mechanism is consistent with the difference in basicities of acetals and orthoformates as acetals are estimated to be approximately two $\mathrm{p} K_{\mathrm{a}}$ units more basic than orthoformates. $^{49,52}$

\section{Rate Accelerations}

In order to compare the rate difference between the catalyzed and the uncatalyzed reaction, the $k_{\text {cat }}$ rate constants from Michaelis-Menten studies were compared to the rate constants for the background reaction for hydrolysis of 2 and 1,1-diethoxymethane (4). This analysis revealed sizeable accelerations of 190 and 980 for $\mathbf{2}$ and $\mathbf{4}$ respectively (2: $\left.k_{\text {cat }}=8.00 \times 10^{-4} \mathrm{~s}^{-1}, k_{\text {uncat }}=4.3 \times 10^{-6} \mathrm{~s}^{-1}, 4: k_{\text {cat }}=4.79 \times 10^{-3} \mathrm{~s}^{-1}, k_{\text {uncat }}=4.9 \times 10^{-6} \mathrm{~s}^{-1}\right)$. The $\mathrm{K}_{\mathrm{M}}$ values, assuming a fast substrate encapsulation pre-equilibrium, can be interpreted as a dissociation constant for the bound acetal since the guest ejection is much faster than the rate constant $k_{\text {cat }}$ for conversion of the encapsulated substrate to product. As expected, the more water soluble 4 has a lower affinity for the interior of 1 (2: 8.09 $\mathrm{mM}$, 4: $31.1 \mathrm{mM})$. Comparison of $k_{\mathrm{cat}} / \mathrm{K}_{\mathrm{M}}$ for the different substrates, often referred to as the specificity factor, allows for comparison of the second-order proportionality constant for the rate of conversion of pre-formed host-substrate complex to product, thereby providing a comparison of how efficiently different substrates can compete for the active site of 1 . Although 4 is more water soluble than 2, as is reflected by the relative $K_{M}$ values for the two substrates, once encapsulated, $\mathbf{4}$ is more readily hydrolyzed by the 
assembly (2: $\left.0.099 \mathrm{M}^{-1} \mathrm{~s}^{-1}, 4: 0.153 \mathrm{M}^{-1} \mathrm{~s}^{-1}\right)$. The catalytic proficiency $\left(\left(k_{\mathrm{cat}} / \mathrm{K}_{\mathrm{M}}\right) / k_{\text {uncat }}\right)$ for different substrates is often used as a measure of how encapsulation affects the transition state stabilization with respect to the uncatalyzed reaction. For substrates 2 and $\mathbf{4}$, the catalytic proficiencies are quite similar $\left(2: 2.28 \times 10^{4} \mathrm{M}^{-1}, 4: 3.12 \times 10^{4} \mathrm{M}^{-1}\right)$, suggesting that the differences in $\mathrm{K}_{\mathrm{M}}$ values for these two substrates is primarily responsible for the difference in the $k_{\text {cat }} / k_{\text {uncat }}$ acceleration.

\section{Conclusions}

In summary, we have expanded our initial study of acetal hydrolysis in basic solution to include a detailed kinetic analysis of the mechanism of catalysis. The initial encapsulation of the neutral substrate is driven by the hydrophobic effect as shown by mixed solvent studies. Kinetic analysis of the rate constants of the catalyzed and uncatalyzed reactions show that the assembly is able to efficiently catalyze the hydrolysis, with rate accelerations of up to $10^{3}$. Further information on the rate-limiting step of the reaction using activation parameters and solvent isotope effects suggest that hydrolysis in 1 changes the mechanism of acetal hydrolysis from an A-1 mechanism to an A-2 mechanism.

\section{Experimental}

General Procedures. All NMR spectra were obtained using an AV-500 MHz spectrometer at the indicated frequency. The temperature of all variable temperature NMR experiments was calibrated with methanol or ethylene glycol standards. ${ }^{53}$ NMR 
spectra measured in $\mathrm{H}_{2} \mathrm{O}$ were obtained using the Watergate solvent suppression sequence. Substrates $\mathbf{2}$ and $\mathbf{4}$ were purchased from commercial suppliers and distilled over powdered $3 \AA$ molecular sieves prior to use. The assembly, $\mathrm{K}_{12}\left[\mathrm{Ga}_{4} \mathrm{~L}_{6}\right]$ was prepared as described in the literature. ${ }^{28}$

General Procedure for Kinetics Runs. In an $\mathrm{N}_{2}$-filled glovebox, 1 was weighed into a $20 \mathrm{~mL}$ scintillation vial at which point $\mathrm{H}_{2} \mathrm{O}$ buffered to the desired $\mathrm{pH}$ and an internal standard (DMSO) were added. The stock solution was divided into NMR tubes in $500 \mu \mathrm{L}$ aliquots. All kinetic runs with $\mathbf{1}$ were performed in the probe by allowing the NMR tube to equilibrate at the desired temperature for 10 minutes at which point the tube was ejected, the substrate injected to the tube, and the tube reinserted into the NMR instrument. Initial rates were measured for the first $5-10 \%$ of the reaction and were determined by integration of the ${ }^{1} \mathrm{H}$ NMR resonances corresponding to the products of the reaction. Both the methanol and ketone/aldehyde products were integrated, except in the solvent isotope studies, in which case only methanol formation was followed due to the possibility of $\mathrm{H} / \mathrm{D}$ exchange of the acetone product at basic $\mathrm{pH}$. All MichaelisMenten kinetic data were fit directly to the Michaelis-Menten equation using non-linear least squares refinement.

Acknowledgment. We thank Courtney Hastings for helpful discussions and experimental assistance and Rudi Nunlist for NMR assistance. This work was supported by the Director, Office of Science, Office of Basic Energy Sciences, and the Division of Chemical Sciences, Geosciences, and Biosciences of the U.S. Department of Energy at 
LBNL under Contract No. DE-AC02-05CH11231 and an NSF predoctoral fellowship to M.D.P.

Supporting Information Available: Kinetic data and plots. This material is available free of charge via the Internet at http://pubs.acs.org.

\section{References}

(1) Das, S.; Brudvig, G. W.; Crabtree, R. H. Chem. Commun. 2008, 413-424.

(2) Schmuck, C. Angew. Chem. Int. Ed. 2007, 46, 5830-5833.

(3) Koblenz, T. S.; Wassenaar, J.; Reek, J. N. H. Chem. Soc. Rev. 2008, 37, 247-262.

(4) Dalgarno, S. J.; Power, N. P.; Atwood, J. L. Coord. Chem. Rev. 2008, 252, 825-

841.

(5) Oshovsky, G. V.; Reinhoudt, D. N.; Verboom, W. Angew. Chem. Int. Ed. 2007, 46, 2366-2393.

(6) Kang, J. M.; Hilmersson, G.; Santamaria, J.; Rebek, J., Jr. J. Am. Chem Soc. 1998, $120,3650-3656$.

(7) Kang, J. M.; Rebek, J., Jr. Nature 1997, 385, 50-52.

(8) Kang, J. M.; Santamaria, J.; Hilmersson, G.; Rebek, J., Jr. J. Am. Chem Soc. 1998, 120, 7389-7390.

(9) Nishioka, Y.; Yamaguchi, T.; Yoshizawa, M.; Fujita, M. J. Am. Chem Soc. 2007, $129,7000-7001$.

(10) Vriezema, D. M.; Aragonès, M. C.; Elemans, J. A. A. W.; Cornelissen, J. J. L. M.; Rowan, A. E.; Nolte, R. J. M. Chem. Rev. 2005, 105, 1445-1489.

(11) Yoshizawa, M.; Fujita, M. Pure and Applied Chemistry 2005, 77, 1107 - 1112. 
(12) Yoshizawa, M.; Tamura, M.; Fujita, M. Science 2006, 312, 251 - 254.

(13) Nishioka, Y.; Yamaguchi, T.; Kawano, M.; Fujita, M. J. Am. Chem Soc. 2008, $1308160-8161$.

(14) Hou, J.-L.; Ajami, D.; Rebek Jr., J. J. Am. Chem Soc. 2008, 130, 7810-7811.

(15) Yamashita, K.; Kawano, M.; Fujita, M. Chem. Commun. 2007, 40, 4102-4103.

(16) Fiedler, D.; Bergman, R. G.; Raymond, K. N. Angew. Chem. Int. Ed. 2004, 43, 6748-6751.

(17) Pluth, M. D.; Bergman, R. G.; Raymond, K. N. Science 2007, 316, 85-88.

(18) Cacciapaglia, R.; Di Stefano, S.; Mandolini, L. Acc. Chem. Res. 2004, 37, $113-$ 122.

(19) Schramm, M. P.; Restorp, P.; Zelder, F.; Rebek Jr., J. J. Am. Chem. Soc. 2008, $130,2450-2451$.

(20) Ryu, E.-H.; Cho, H.; Zhao, Y. Org. Lett. 2007, 9, 5147-5150

(21) Krishnaveni, N. S.; Surendra, K.; Reddy, M. A.; Nageswar, Y. V. D.; Rao, K. R. J. Org. Chem. 2003, 68, 2018-2019.

(22) Bjerre, J.; Nielsen, E. H.; Bols, M. Eur. J. Org. Chem. 2008, 4, 745-752.

(23) Ortega-Caballero, F.; Bols, M. Can. J. Chem. 2006, 84, 650-658.

(24) Ortega-Caballero, F.; Rousseau, C.; Christensen, B.; Petersen, T. E.; Bols, M. J. Am. Chem. Soc. 2005, 127, 3238-3239.

(25) Rousseau, C.; Christensen, B.; Bols, M. Eur. J. Org. Chem 2005, 13, 2734-2739.

(26) Functionalized cyclodextrins have been used as catalysts for other types of reaction with high rate accelerations. For example, the oxidation of substituted benzyl 
alcohols has been accelerated by $\sim 6 \times 10^{4}$, see Marinescu, L. G.; Bols, M. Angew. Chem. Int. Ed. 2006, 45, 4590-4593.

(27) Caulder, D. L.; Bruckner, C.; Powers, R. E.; Konig, S.; Parac, T. N.; Leary, J. A.; Raymond, K. N. J. Am. Chem. Soc. 2001, 123, 8923-8938.

(28) Caulder, D. L.; Powers, R. E.; Parac, T. N.; Raymond, K. N. Angew. Chem. Int. Ed. 1998, 37, 1840-1843.

(29) Caulder, D. L.; Raymond, K. N. J. Chem. Soc., Dalton. Trans. 1999, 8, $1185-$ 1200.

(30) Biros, S. M.; Bergman, R. G.; Raymond, K. N. J. Am. Chem Soc. 2007, 129, 12094-12095.

(31) Davis, A. V.; Raymond, K. N. J. Am. Chem. Soc. 2005, 127, 7912-7919.

(32) Fiedler, D.; van Halbeek, H.; Bergman, R. G.; Raymond, K. N. J. Am. Chem. Soc. 2006, 128, 10240-10252.

(33) Hastings, C. J.; Fiedler, D.; Bergman, R. G.; Raymond, K. N. J. Am. Chem. Soc. 2008, 130, 10977-10983.

(34) Pluth, M. D.; Bergman, R. G.; Raymond, K. N. J. Am. Chem. Soc. 2007, 129, 11459-11467.

(35) Pluth, M. D.; Bergman, R. G.; Raymond, K. N. J. Am. Chem. Soc. 2008, 130, 6362-6366.

(36) Pluth, M. D.; Bergman, R. G.; Raymond, K. N. J. Am. Chem. Soc. 2008, 30, 11423-11429.

(37) Pluth, M. D.; Bergman, R. G.; Raymond, K. N. Angew. Chem. Int. Ed. 2007, 46, 8587-8589. 
(38) Ates, A.; Gautier, A.; Leroy, B.; Plancher, J.-M.; Quesnel, Y.; Vanherck, J.-C.;

Marko, I. E. Tetrahedron 2003, 59, 8989-8999.

(39) Carrigan, M. D.; Sarapa, D.; Smith, R. C.; Wieland, L. C.; Mohan, R. S. J. Org. Chem. 2002, 67, 1027-1030.

(40) Dalpozzo, R.; De Nino, A.; Maiuolo, L.; Procopio, A.; Tagarelli, A.; Sindona, G.; Bartoli, G. J. Org. Chem. 2002, 67, 9093-9095.

(41) Eash, K. J.; Pulia, M. S.; Wieland, L. C.; Mohan, R. S. J. Org. Chem. 2000, 65, 8399-8401.

(42) Mirjalili, B. F.; Zolfigol, M. A.; Bamoniri, A. Molecules 2002, 7, 751-755.

(43) Marko, I. E.; Ates, A.; Gautier, A.; Leroy, B.; Plancher, J.-M.; Quesnel, Y.; Vanherck, J.-C. Angew. Chem. Int. Ed. 1999, 38, 3207-3209.

(44) The acetone product formed in the reaction is stable under the reaction conditions and does not undergo an aldol reaction to form mesityl oxide.

(45) Breslow, R. Acc. Chem. Res. 1991, 24, 159-164.

(46) In contrast to the solvent dependence observed for neutral guest encapsulation, we have previously shown that protonated guests are readily encapsulated in either aqueous or polar organic solvents.

(47) Bell, R. P. The Proton in Chemistry; 2 ed.; Cornell University Press: Ithica, New York, 1973.

(48) Cordes, E. H. Progr. Phys. Org. Chem. 1967, 4, 1-44.

(49) Cordes, E. H.; Bull, H. G. Chem. Rev. 1974, 74, 581-603.

(50) In basic $\mathrm{D}_{2} \mathrm{O}$ solution, the methyl hydrogens of the acetone product slowly undergo H/D exchange with the solvent. However, under the time course of the reaction 
the rate of exchange is negligible. Furthermore, at the concentrations of the kinetic runs, complete $\mathrm{H} / \mathrm{D}$ exchange would form less than $1 \%$ of $\mathrm{HDO}$ and therefore has been ignored.

(51) A-2 mechanisms are often accompanied by more negative entropies of activation that $\mathrm{A}-\mathrm{S}_{\mathrm{E}} 2$ mechanisms. One possible explanation for the attenuated negative entropy of activation for the hydrolysis of $\mathbf{2}$ in $\mathbf{1}$ is that encapsulation of the substrate (and possibly water) in the interior cavity diminishes the entropic penalty generally associated with bringing the acetal and water molecules together. This hypothesis is consistent with previous mechanistic studies of the aza-Cope rearrangement in $\mathbf{1}$ in which the entropy of activation for reactions occurring in $\mathbf{1}$ was more positive than in free solution (see ref. $32)$.

(52) Pletcher, T.; Cordes, E. J. Org. Chem. 1967, 32, 2294-2297.

(53) Ammann, C.; Meier, P.; Merbach, A. E. J. Magn. Reson. A 1982, 46, 319-321. 


\section{TOC Figure}

Mechanistic Studies of the Hydrolysis of Acetals in Basic Solution Catalyzed by a Supramolecular Assembly

Michael D. Pluth, Robert G. Bergman,* and Kenneth N. Raymond*

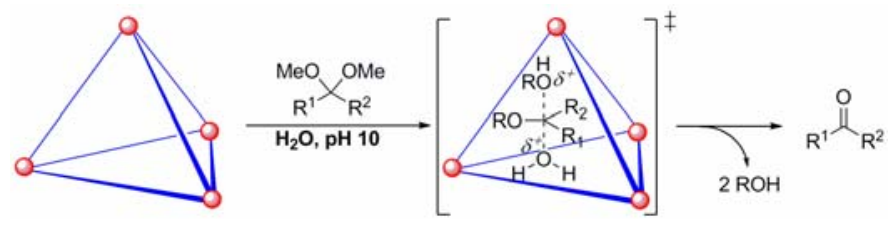

